\title{
Lower tubulin expression in glioblastoma stem cells attenuates efficacy of microtubule-
}

targeting agents

Ramzi H. Abbassi ${ }^{\mathbf{1}}$, Ariadna Recasens ${ }^{\mathbf{1}}$, Dinesh C. Indurthi ${ }^{\mathbf{1}}$, Terrance G. Johns ${ }^{\mathbf{2}}$, Brett W. Stringer ${ }^{\mathbf{3}}$, Bryan W. Day ${ }^{3}$, Lenka Munoz ${ }^{*}$

${ }^{1}$ Faculty of Medicine and Health, Charles Perkins Centre, The University of Sydney, NSW 2006, Australia

${ }^{2}$ Oncogenic Signalling Laboratory and Brain Cancer Discovery Collaborative, Telethon Kids Institute, Perth Children's Hospital, 15 Hospital Avenue, Nedlands, WA 6009, Australia

${ }^{3}$ QIMR Berghofer Medical Research Institute, 300 Herston Road, Herston, QLD 4006, Australia

\section{Supplementary Information}

Table S1. Genotypes of glioblastoma stem cell lines.

Table S2. Details of primary antibodies.

Table S3. Colchicine sensitivity metric values.

Table S4. Nocodazole sensitivity metric values.

Table S5. Tivantinib sensitivity metric values.

Table S6. CMPD1 sensitivity metric values.

Table S7. Spearman's correlation coefficients between colchicine sensitivity metrics (Table S3) with tubulin code (Figure S2).

Table S8. Spearman's correlation coefficients between nocodazole sensitivity metrics (Table S4) with tubulin code (Figure S2).

Table S9. Spearman's correlation coefficients between tivantinib sensitivity metrics (Table S5) with tubulin code (Figure S2).

Table S10. Spearman's correlation coefficients between CMPD1 sensitivity metrics (Table S6) with tubulin code (Figure S2).

Figure S1. Representative image of Coomassie stained gel to demonstrate equal protein load across 15 cell lines.

Figure S2. Expression of tubulin isotypes and post-translational modifications normalised to A172 signals.

Figure S3. Expression of tubulin isotypes and post-translational modifications normalised to RN1 signals.

Figure S4. Dose-response curves for MTAs in glioblastoma cell lines.

Figure S5. Spearman's correlations between tubulin expression and MTAs efficacy excluding BAH1 data.

Figure S6. Inhibitors of efflux pumps do not alter the efficacy of MTAs. 
Table S1. Genotypes of glioblastoma stem cell lines.

\begin{tabular}{|c|c|c|c|c|c|c|c|c|c|c|c|c|c|}
\hline \multirow[b]{2}{*}{ Pathway } & \multirow[b]{2}{*}{ Gene } & \multicolumn{4}{|c|}{ Classical } & \multicolumn{4}{|c|}{ Mesenchymal } & \multicolumn{4}{|c|}{ Proneural } \\
\hline & & WK1 & PB1 & HW1 & SB2b & RN1 & FPW1 & RKI1 & MN1 & JK2 & SJH1 & MMK1 & BAH1 \\
\hline \multirow[t]{2}{*}{ RTK } & $M E T$ & & & & $\mathrm{C} 800 \mathrm{~F}$ & T992I & & & E168D & & $\mathrm{H} 289 \mathrm{R}$ & & \\
\hline & ЕРHA2 & & & & & & & & & & $\begin{array}{l}\text { V589M } \\
\text { R721Q }\end{array}$ & & \\
\hline \multirow{3}{*}{ PI3K } & PIK3CA & H1047Y & & & Y1021H & & & & & & & & \\
\hline & PIK3RI & & & & & & & & & & & & \\
\hline & PTEN & & R130* & Spl jnct & & & R130Q & & & & & F56V & V133I \\
\hline \multirow{2}{*}{ MAPK } & $N F 1$ & & & & & & Spl jnct & & & & Spl jnct & & \\
\hline & $M Y C$ & & & & & & & & & & & & \\
\hline \multirow{2}{*}{ P53 } & TP53 & & & & & & & & & R110L & G105C & & \\
\hline & $M D M 2$ & & & & W329C & & & & & & & & \\
\hline RB1 & $C D K N 2 A$ & & & & & & & & & & & & \\
\hline
\end{tabular}


Table S2. Details of primary antibodies.

\begin{tabular}{|c|c|c|}
\hline Antibody & Supplier & Identifier \\
\hline Total $\alpha$-tubulin & Cell Signaling Technology & Cat\# 2144, RRID: AB_2210548 \\
\hline Total $\beta$-tubulin & Abcam & Cat\# ab6046, RRID: AB_2210370 \\
\hline Total $\gamma$-tubulin & Cell Signaling Technology & Cat\# 5886, RRID: AB_10836184 \\
\hline$\beta$ I-tubulin & Abcam & Cat\# ab179511 \\
\hline$\beta$ II-tubulin & Abcam & Cat\# ab179512 \\
\hline$\beta$ III-tubulin & Abcam & Cat\# ab18207, RRID: AB_444319 \\
\hline$\beta I V-t u b u l i n$ & Abcam & Cat\# ab11315, RRID: AB_297919 \\
\hline Tyrosinated $\alpha$-tubulin & MerckMillipore & Cat\# ABT171 \\
\hline Detyrosinated $\alpha$-tubulin & MerckMillipore & Cat\# AB3201; RRID: AB_177350 \\
\hline$\Delta 2 \alpha$-tubulin & MerckMillipore & Cat\# AB3202; RRID: AB_177351 \\
\hline Acetyl K40 $\alpha$-tubulin & Abcam & Cat\# ab179484; \\
\hline Phospho S172 $\beta$ III-tubulin & Abcam & Cat\# ab76286; RRID: AB_1523210 \\
\hline Polyglutaminated $\alpha \beta$-tubulin & Adipogen & Cat\# AG-20B-0020; RRID: AB_2490210 \\
\hline SOX2 & R\&D Systems & Cat\# AF2018; RRID: AB 355110 \\
\hline GAPDH & Cell Signaling Technology & Cat\# 97166 \\
\hline Nestin & R\&D Systems & Cat\# MAB1259; AB_2251304 \\
\hline Rabbit IgG, HRP-linked & Cell Signaling Technology & Cat\# 7074; RRID: AB_2099233 \\
\hline Mouse IgG, HRP-linked & Cell Signaling Technology & Cat\# 7076; RRID: AB_330924 \\
\hline Mouse IgG, Alexa Fluor 488 & Life Technologies & Cat\# A10680; RRID: AB_2534062 \\
\hline Rabbit IgG, AlexaFluor594 & Life Technologies & Cat\# A11012; RRID: AB_141359 \\
\hline FITC-conjugated CD243 (MDR1) & ThermoFisher Scientific & Cat\# 11-2439-41, RRID: AB_11220073 \\
\hline PE-eFluor610-conjugated p-Erk1/2 & ThermoFisher Scientific & Cat\# 61-109-41 \\
\hline APC-conjugated p-p38 MAPK & ThermoFisher Scientific & Cat\# 17-9078-42; RRID: AB_2573290 \\
\hline $\begin{array}{l}\text { Anti-Rabbit Detection Module for Jess, Wes, Peggy Sue or Sally } \\
\text { Sue }\end{array}$ & ProteinSimple & Cat\# DM-001 \\
\hline
\end{tabular}


Table S3. Colchicine sensitivity metric values.

\begin{tabular}{|c|c|c|c|c|c|c|c|c|}
\hline Cell line & $\begin{array}{l}\text { Colchicine } \\
\text { IC }_{50}(\mu \mathrm{M})\end{array}$ & $\begin{array}{c}\text { Colchicine } \\
\mathbf{E}_{\max }\end{array}$ & $\begin{array}{c}\text { Colchicine } \\
\mathbf{h}\end{array}$ & $\begin{array}{c}\text { Colchicine } \\
\text { AUC }\end{array}$ & $\begin{array}{l}\text { Colchicine } \\
\operatorname{GR}_{50}(\mu \mathrm{M})\end{array}$ & $\begin{array}{c}\text { Colchicine } \\
\text { GR }_{\max }\end{array}$ & $\begin{array}{c}\text { Colchicine } \\
\mathbf{h}_{\mathrm{GR}}\end{array}$ & $\begin{array}{l}\text { Colchicine } \\
\text { GR }_{\text {AOC }}\end{array}$ \\
\hline $\mathbf{A} 172$ & $0.013 \pm 0.002$ & $0.151 \pm 0.008$ & $3.547 \pm 0.917$ & $0.639 \pm 0.041$ & $0.013 \pm 0.002$ & $0.042 \pm 0.018$ & $3.613 \pm 0.808$ & $0.389 \pm 0.036$ \\
\hline U87 & $0.013 \pm 0.003$ & $0.243 \pm 0.036$ & $1.960 \pm 0.250$ & $0.624 \pm 0.014$ & $0.011 \pm 0.002$ & $0.034 \pm 0.072$ & $2.125 \pm 0.045$ & $0.454 \pm 0.024$ \\
\hline $\mathbf{U} 251$ & $0.013 \pm 0.001$ & $0.156 \pm 0.001$ & $3.260 \pm 0.400$ & $0.633 \pm 0.024$ & $0.015 \pm 0.001$ & $0.159 \pm 0.002$ & $3.400 \pm 0.500$ & $0.346 \pm 0.017$ \\
\hline WK1 & $0.019 \pm 0.001$ & $0.159 \pm 0.001$ & $2.350 \pm 0.160$ & $0.640 \pm 0.013$ & $0.013 \pm 0.001$ & $-0.486 \pm 0.001$ & $2.465 \pm 0.105$ & $0.619 \pm 0.019$ \\
\hline PB1 & $0.012 \pm 0.001$ & $0.241 \pm 0.009$ & $2.500 \pm 0.030$ & $0.659 \pm 0.011$ & $0.008 \pm 0.001$ & $-0.253 \pm 0.019$ & $2.070 \pm 0.080$ & $0.539 \pm 0.017$ \\
\hline HW1 & $0.008 \pm 0.001$ & $0.226 \pm 0.002$ & $3.465 \pm 0.075$ & $0.599 \pm 0.009$ & $0.007 \pm 0.001$ & $-0.046 \pm 0.005$ & $3.375 \pm 0.075$ & $0.517 \pm 0.011$ \\
\hline SB2b & $0.020 \pm 0.009$ & $0.128 \pm 0.009$ & $4.193 \pm 0.807$ & $0.666 \pm 0.016$ & $0.018 \pm 0.004$ & $-0.394 \pm 0.024$ & $3.160 \pm 0.954$ & $0.514 \pm 0.023$ \\
\hline RN1 & $0.007 \pm 0.001$ & $0.129 \pm 0.011$ & $4.805 \pm 0.195$ & $0.546 \pm 0.021$ & $0.006 \pm 0.001$ & $-0.453 \pm 0.030$ & $4.675 \pm 0.225$ & $0.736 \pm 0.036$ \\
\hline FPW1 & $0.017 \pm 0.001$ & $0.179 \pm 0.001$ & $2.980 \pm 0.590$ & $0.659 \pm 0.013$ & $0.014 \pm 0.002$ & $-0.237 \pm 0.002$ & $3.220 \pm 0.630$ & $0.499 \pm 0.015$ \\
\hline RKI1 & $0.024 \pm 0.005$ & $0.347 \pm 0.011$ & $2.797 \pm 0.310$ & $0.746 \pm 0.019$ & $0.021 \pm 0.004$ & $0.204 \pm 0.018$ & $2.667 \pm 0.222$ & $0.304 \pm 0.022$ \\
\hline MN1 & $0.014 \pm 0.004$ & $0.167 \pm 0.005$ & $2.650 \pm 0.123$ & $0.624 \pm 0.029$ & $0.010 \pm 0.003$ & $-0.475 \pm 0.011$ & $2.610 \pm 0.110$ & $0.647 \pm 0.048$ \\
\hline JK2 & $0.013 \pm 0.001$ & $0.253 \pm 0.020$ & $2.493 \pm 0.282$ & $0.646 \pm 0.022$ & $0.011 \pm 0.001$ & $0.014 \pm 0.040$ & $2.593 \pm 0.364$ & $0.446 \pm 0.030$ \\
\hline SJH1 & $0.004 \pm 0.001$ & $0.249 \pm 0.016$ & $2.300 \pm 0.233$ & $0.543 \pm 0.017$ & $0.002 \pm 0.001$ & $-0.606 \pm 0.029$ & $2.293 \pm 0.229$ & $0.989 \pm 0.037$ \\
\hline MMK1 & $0.022 \pm 0.007$ & $0.231 \pm 0.037$ & $1.755 \pm 0.675$ & $0.672 \pm 0.020$ & $0.022 \pm 0.007$ & $0.099 \pm 0.070$ & $1.750 \pm 0.550$ & $0.356 \pm 0.018$ \\
\hline BAH1 & $0.012 \pm 0.001$ & $0.146 \pm 0.028$ & $2.550 \pm 0.170$ & $0.606 \pm 0.035$ & $0.009 \pm 0.001$ & $-0.486 \pm 0.001$ & $2.460 \pm 0.140$ & $0.619 \pm 0.019$ \\
\hline
\end{tabular}


Table S4. Nocodazole sensitivity metric values.

\begin{tabular}{|c|c|c|c|c|c|c|c|c|}
\hline Cell line & $\begin{array}{c}\text { Nocodazole } \\
\text { IC }_{50}(\mu \mathbf{M})\end{array}$ & $\begin{array}{l}\text { Nocodazole } \\
\mathbf{E}_{\max }\end{array}$ & $\begin{array}{c}\text { Nocodazole } \\
\mathbf{h}\end{array}$ & $\begin{array}{c}\text { Nocodazole } \\
\text { AUC }\end{array}$ & $\begin{array}{c}\text { Nocodazole } \\
\operatorname{GR}_{50}(\mu M)\end{array}$ & $\begin{array}{c}\text { Nocodazole } \\
\text { GR }_{\max }\end{array}$ & $\begin{array}{c}\text { Nocodazole } \\
\mathbf{h}_{\mathrm{GR}}\end{array}$ & $\begin{array}{c}\text { Nocodazole } \\
\text { GR }_{\text {AOC }}\end{array}$ \\
\hline $\mathbf{A} 172$ & $0.062 \pm 0.018$ & $0.161 \pm 0.009$ & $2.580 \pm 0.455$ & $0.534 \pm 0.030$ & $0.090 \pm 0.038$ & $0.063 \pm 0.021$ & $1.780 \pm 0.312$ & $0.471 \pm 0.041$ \\
\hline U87 & $0.065 \pm 0.001$ & $0.251 \pm 0.038$ & $2.465 \pm 0.575$ & $0.594 \pm 0.015$ & $0.059 \pm 0.002$ & $0.050 \pm 0.074$ & $2.310 \pm 0.630$ & $0.491 \pm 0.033$ \\
\hline $\mathrm{U} 251$ & $0.040 \pm 0.012$ & $0.161 \pm 0.006$ & $3.105 \pm 0.805$ & $0.494 \pm 0.025$ & $0.049 \pm 0.011$ & $0.168 \pm 0.013$ & $2.915 \pm 0.835$ & $0.474 \pm 0.018$ \\
\hline WK1 & $0.070 \pm 0.015$ & $0.173 \pm 0.003$ & $1.360 \pm 0.330$ & $0.541 \pm 0.001$ & $0.036 \pm 0.004$ & $-0.453 \pm 0.007$ & $1.355 \pm 0.245$ & $0.776 \pm 0.001$ \\
\hline PB1 & $0.155 \pm 0.085$ & $0.265 \pm 0.024$ & $1.245 \pm 0.266$ & $0.653 \pm 0.037$ & $0.062 \pm 0.028$ & $-0.203 \pm 0.051$ & $1.036 \pm 0.274$ & $0.538 \pm 0.061$ \\
\hline HW1 & $0.061 \pm 0.002$ & $0.245 \pm 0.001$ & $2.090 \pm 0.030$ & $0.557 \pm 0.010$ & $0.053 \pm 0.002$ & $-0.009 \pm 0.001$ & $2.855 \pm 0.295$ & $0.563 \pm 0.010$ \\
\hline SB2b & $0.062 \pm 0.004$ & $0.154 \pm 0.010$ & $3.685 \pm 0.015$ & $0.567 \pm 0.013$ & $0.054 \pm 0.004$ & $-0.324 \pm 0.025$ & $3.530 \pm 0.010$ & $0.655 \pm 0.012$ \\
\hline RN1 & $0.045 \pm 0.009$ & $0.185 \pm 0.063$ & $3.225 \pm 0.605$ & $0.558 \pm 0.091$ & $0.036 \pm 0.007$ & $-0.310 \pm 0.137$ & $2.805 \pm 0.295$ & $0.697 \pm 0.154$ \\
\hline FPW1 & $0.081 \pm 0.007$ & $0.185 \pm 0.001$ & $3.190 \pm 0.270$ & $0.597 \pm 0.025$ & $0.070 \pm 0.007$ & $-0.225 \pm 0.002$ & $3.085 \pm 0.255$ & $0.581 \pm 0.032$ \\
\hline RKI1 & $0.111 \pm 0.022$ & $0.365 \pm 0.035$ & $1.773 \pm 0.185$ & $0.734 \pm 0.070$ & $0.093 \pm 0.019$ & $0.232 \pm 0.057$ & $1.610 \pm 0.211$ & $0.308 \pm 0.084$ \\
\hline MN1 & $0.047 \pm 0.024$ & $0.210 \pm 0.028$ & $3.070 \pm 0.206$ & $0.625 \pm 0.099$ & $0.034 \pm 0.018$ & $-0.380 \pm 0.061$ & $3.023 \pm 0.209$ & $0.639 \pm 0.175$ \\
\hline JK2 & $0.058 \pm 0.024$ & $0.270 \pm 0.035$ & $1.991 \pm 0.595$ & $0.563 \pm 0.058$ & $0.049 \pm 0.021$ & $0.046 \pm 0.069$ & $1.923 \pm 0.452$ & $0.545 \pm 0.079$ \\
\hline SJH1 & $0.034 \pm 0.009$ & $0.278 \pm 0.017$ & $3.665 \pm 0.580$ & $0.519 \pm 0.040$ & $0.021 \pm 0.007$ & $-0.553 \pm 0.032$ & $3.855 \pm 0.662$ & $1.047 \pm 0.086$ \\
\hline MMK1 & $0.064 \pm 0.006$ & $0.247 \pm 0.025$ & $2.197 \pm 0.171$ & $0.595 \pm 0.008$ & $0.066 \pm 0.006$ & $0.131 \pm 0.046$ & $2.063 \pm 0.259$ & $0.441 \pm 0.006$ \\
\hline BAH1 & $0.055 \pm 0.004$ & $0.155 \pm 0.020$ & $1.750 \pm 0.020$ & $0.536 \pm 0.006$ & $0.036 \pm 0.003$ & $-0.411 \pm 0.049$ & $1.625 \pm 0.015$ & $0.731 \pm 0.004$ \\
\hline
\end{tabular}


Table S5. Tivantinib sensitivity metric values.

\begin{tabular}{|c|c|c|c|c|c|c|c|c|}
\hline Cell line & $\begin{array}{l}\text { Tivantinib } \\
\text { IC }_{50}(\mu M)\end{array}$ & $\begin{array}{c}\text { Tivantinib } \\
\mathbf{E}_{\max }\end{array}$ & $\begin{array}{c}\text { Tivantinib } \\
\mathbf{h}\end{array}$ & $\begin{array}{c}\text { Tivantinib } \\
\text { AUC }\end{array}$ & $\begin{array}{l}\text { Tivantinib } \\
\operatorname{GR}_{50}(\mu M)\end{array}$ & $\begin{array}{l}\text { Tivantinib } \\
\text { GR }_{\max }\end{array}$ & $\begin{array}{c}\text { Tivantinib } \\
\mathbf{h}_{\mathrm{GR}}\end{array}$ & $\begin{array}{l}\text { Tivantinib } \\
\text { GR }_{\text {AOC }}\end{array}$ \\
\hline A172 & $0.438 \pm 0.045$ & $0.135 \pm 0.020$ & $2.757 \pm 0.736$ & $0.517 \pm 0.008$ & $0.508 \pm 0.058$ & $-0.004 \pm 0.055$ & $2.040 \pm 0.158$ & $0.509 \pm 0.016$ \\
\hline U87 & $0.690 \pm 0.028$ & $0.225 \pm 0.026$ & $2.010 \pm 0.720$ & $0.588 \pm 0.003$ & $0.614 \pm 0.001$ & $-0.003 \pm 0.053$ & $1.850 \pm 0.740$ & $0.497 \pm 0.021$ \\
\hline $\mathrm{U} 251$ & $0.488 \pm 0.105$ & $0.159 \pm 0.012$ & $3.535 \pm 1.385$ & $0.523 \pm 0.017$ & $0.611 \pm 0.067$ & $0.163 \pm 0.024$ & $3.305 \pm 1.365$ & $0.442 \pm 0.003$ \\
\hline WK1 & $0.811 \pm 0.129$ & $0.250 \pm 0.047$ & $1.268 \pm 0.339$ & $0.691 \pm 0.073$ & $0.361 \pm 0.083$ & $-0.287 \pm 0.099$ & $1.231 \pm 0.334$ & $0.507 \pm 0.127$ \\
\hline PB1 & $3.710 \pm 0.430$ & $0.108 \pm 0.016$ & $0.546 \pm 0.020$ & $0.668 \pm 0.012$ & $1.220 \pm 0.210$ & $-0.572 \pm 0.043$ & $0.531 \pm 0.034$ & $0.521 \pm 0.018$ \\
\hline HW1 & $0.973 \pm 0.368$ & $0.185 \pm 0.004$ & $0.946 \pm 0.135$ & $0.574 \pm 0.028$ & $0.712 \pm 0.272$ & $-0.139 \pm 0.009$ & $0.805 \pm 0.158$ & $0.532 \pm 0.038$ \\
\hline SB2b & $0.523 \pm 0.059$ & $0.132 \pm 0.002$ & $3.180 \pm 0.390$ & $0.538 \pm 0.005$ & $0.440 \pm 0.064$ & $-0.383 \pm 0.005$ & $2.965 \pm 0.455$ & $0.705 \pm 0.003$ \\
\hline RN1 & $0.242 \pm 0.001$ & $0.095 \pm 0.024$ & $2.575 \pm 0.185$ & $0.443 \pm 0.010$ & $0.194 \pm 0.004$ & $-0.526 \pm 0.074$ & $2.445 \pm 0.225$ & $0.889 \pm 0.018$ \\
\hline FPW1 & $0.760 \pm 0.003$ & $0.129 \pm 0.001$ & $2.000 \pm 0.440$ & $0.566 \pm 0.010$ & $0.578 \pm 0.037$ & $-0.368 \pm 0.002$ & $1.735 \pm 0.455$ & $0.621 \pm 0.012$ \\
\hline RKI1 & $4.105 \pm 0.665$ & $0.231 \pm 0.043$ & $0.758 \pm 0.085$ & $0.732 \pm 0.021$ & $3.435 \pm 0.325$ & $-0.018 \pm 0.089$ & $0.644 \pm 0.083$ & $0.313 \pm 0.029$ \\
\hline MN1 & $1.137 \pm 0.720$ & $0.126 \pm 0.016$ & $1.615 \pm 0.529$ & $0.554 \pm 0.043$ & $0.412 \pm 0.147$ & $-0.576 \pm 0.039$ & $1.556 \pm 0.519$ & $0.758 \pm 0.080$ \\
\hline JK2 & $0.621 \pm 0.164$ & $0.198 \pm 0.032$ & $1.446 \pm 0.239$ & $0.654 \pm 0.048$ & $0.539 \pm 0.192$ & $-0.008 \pm 0.109$ & $1.307 \pm 0.257$ & $0.425 \pm 0.064$ \\
\hline SJH1 & $0.172 \pm 0.038$ & $0.236 \pm 0.005$ & $3.623 \pm 0.795$ & $0.492 \pm 0.022$ & $0.093 \pm 0.011$ & $-0.629 \pm 0.010$ & $3.645 \pm 0.782$ & $1.104 \pm 0.047$ \\
\hline MMK1 & $0.533 \pm 0.121$ & $0.131 \pm 0.005$ & $1.186 \pm 0.169$ & $0.601 \pm 0.091$ & $0.614 \pm 0.144$ & $0.039 \pm 0.162$ & $0.916 \pm 0.187$ & $0.434 \pm 0.110$ \\
\hline BAH1 & $0.446 \pm 0.004$ & $0.122 \pm 0.027$ & $1.895 \pm 0.025$ & $0.537 \pm 0.004$ & $0.293 \pm 0.003$ & $-0.496 \pm 0.072$ & $1.705 \pm 0.025$ & $0.727 \pm 0.009$ \\
\hline
\end{tabular}


Table S6. CMPD1 sensitivity metric values.

\begin{tabular}{|c|c|c|c|c|c|c|c|c|}
\hline Cell line & $\begin{array}{c}\text { CMPD1 } \\
\text { IC }_{50}(\mu M)\end{array}$ & $\begin{array}{c}\text { CMPD1 } \\
\mathbf{E}_{\max }\end{array}$ & $\begin{array}{c}\text { CMPD1 } \\
\text { h }\end{array}$ & $\begin{array}{c}\text { CMPD1 } \\
\text { AUC }\end{array}$ & $\begin{array}{c}\text { CMPD1 } \\
\text { GR }_{50}(\mu M)\end{array}$ & $\begin{array}{l}\text { CMPD1 } \\
\text { GR }_{\max }\end{array}$ & $\begin{array}{c}\text { CMPD1 } \\
\mathbf{h}_{\mathrm{GR}}\end{array}$ & $\begin{array}{c}\text { CMPD1 } \\
\text { GR }_{\text {AOC }}\end{array}$ \\
\hline A172 & $0.321 \pm 0.054$ & $0.143 \pm 0.017$ & $1.985 \pm 0.325$ & $0.493 \pm 0.024$ & $0.369 \pm 0.066$ & $0.019 \pm 0.044$ & $2.587 \pm 0.734$ & $0.534 \pm 0.022$ \\
\hline U87 & $0.386 \pm 0.095$ & $0.200 \pm 0.036$ & $1.795 \pm 0.685$ & $0.522 \pm 0.021$ & $0.328 \pm 0.061$ & $-0.059 \pm 0.087$ & $1.606 \pm 0.615$ & $0.584 \pm 0.050$ \\
\hline $\mathrm{U} 251$ & $0.301 \pm 0.050$ & $0.148 \pm 0.007$ & $3.910 \pm 0.870$ & $0.489 \pm 0.007$ & $0.357 \pm 0.030$ & $0.140 \pm 0.016$ & $3.270 \pm 0.340$ & $0.476 \pm 0.009$ \\
\hline WK1 & $0.613 \pm 0.031$ & $0.166 \pm 0.030$ & $1.180 \pm 0.040$ & $0.548 \pm 0.017$ & $0.273 \pm 0.005$ & $-0.472 \pm 0.070$ & $1.037 \pm 0.103$ & $0.755 \pm 0.030$ \\
\hline PB1 & $1.985 \pm 0.635$ & $0.215 \pm 0.007$ & $0.784 \pm 0.181$ & $0.643 \pm 0.008$ & $0.661 \pm 0.113$ & $-0.311 \pm 0.015$ & $0.603 \pm 0.108$ & $0.556 \pm 0.014$ \\
\hline HW1 & $0.685 \pm 0.030$ & $0.149 \pm 0.008$ & $3.140 \pm 0.380$ & $0.581 \pm 0.004$ & $0.629 \pm 0.036$ & $-0.225 \pm 0.020$ & $2.111 \pm 1.299$ & $0.537 \pm 0.002$ \\
\hline SB2b & $0.514 \pm 0.173$ & $0.145 \pm 0.012$ & $3.205 \pm 0.035$ & $0.537 \pm 0.039$ & $0.434 \pm 0.147$ & $-0.349 \pm 0.029$ & $3.040 \pm 0.020$ & $0.696 \pm 0.061$ \\
\hline RN1 & $0.466 \pm 0.016$ & $0.138 \pm 0.005$ & $3.065 \pm 0.175$ & $0.502 \pm 0.003$ & $0.380 \pm 0.020$ & $-0.430 \pm 0.013$ & $3.015 \pm 0.275$ & $0.799 \pm 0.007$ \\
\hline FPW1 & $0.867 \pm 0.148$ & $0.160 \pm 0.016$ & $2.440 \pm 0.245$ & $0.573 \pm 0.032$ & $0.704 \pm 0.114$ & $-0.286 \pm 0.039$ & $2.263 \pm 0.241$ & $0.614 \pm 0.049$ \\
\hline RKI1 & $2.673 \pm 0.366$ & $0.230 \pm 0.015$ & $1.111 \pm 0.162$ & $0.689 \pm 0.055$ & $1.965 \pm 0.510$ & $-0.013 \pm 0.031$ & $1.061 \pm 0.224$ & $0.372 \pm 0.065$ \\
\hline MN1 & $0.693 \pm 0.205$ & $0.150 \pm 0.015$ & $2.137 \pm 0.316$ & $0.635 \pm 0.066$ & $0.476 \pm 0.151$ & $-0.517 \pm 0.035$ & $2.073 \pm 0.290$ & $0.622 \pm 0.118$ \\
\hline JK2 & $1.229 \pm 0.301$ & $0.230 \pm 0.035$ & $1.169 \pm 0.180$ & $0.608 \pm 0.021$ & $0.940 \pm 0.225$ & $-0.041 \pm 0.078$ & $1.189 \pm 0.272$ & $0.477 \pm 0.029$ \\
\hline SJH1 & $0.953 \pm 0.129$ & $0.227 \pm 0.004$ & $1.607 \pm 0.535$ & $0.626 \pm 0.032$ & $0.435 \pm 0.156$ & $-0.646 \pm 0.007$ & $1.641 \pm 0.538$ & $0.818 \pm 0.071$ \\
\hline MMK1 & $1.960 \pm 0.455$ & $0.163 \pm 0.012$ & $1.028 \pm 0.074$ & $0.621 \pm 0.019$ & $2.010 \pm 0.415$ & $-0.044 \pm 0.029$ & $0.974 \pm 0.128$ & $0.411 \pm 0.024$ \\
\hline BAH1 & $0.518 \pm 0.006$ & $0.123 \pm 0.025$ & $1.965 \pm 0.055$ & $0.531 \pm 0.006$ & $0.352 \pm 0.008$ & $-0.492 \pm 0.068$ & $1.790 \pm 0.080$ & $0.747 \pm 0.014$ \\
\hline
\end{tabular}


Table S7. Spearman's correlation coefficients between colchicine sensitivity metrics (Table S3) with tubulin code (Figure S2). $(* \mathbf{P}<\mathbf{0 . 0 5} ; * * \mathbf{P}<\mathbf{0 . 0 1} ; * * * \mathbf{P}<\mathbf{0 . 0 0 5} ; * * * * \mathbf{P}<\mathbf{0 . 0 0 1})$

\begin{tabular}{|l|c|c|c|c|c|c|c|c|}
\hline & $\begin{array}{c}\text { Colchicine } \\
\text { IC }_{\mathbf{5 0}}\end{array}$ & $\begin{array}{c}\text { Colchicine } \\
\mathbf{E}_{\mathbf{m a x}}\end{array}$ & $\begin{array}{c}\text { Colchicine } \\
\mathbf{h}\end{array}$ & $\begin{array}{c}\text { Colchicine } \\
\text { AUC }\end{array}$ & $\begin{array}{c}\text { Colchicine } \\
\mathbf{G R}_{\mathbf{5 0}}\end{array}$ & $\begin{array}{c}\text { Colchicine } \\
\text { GR }_{\text {max }}\end{array}$ & $\begin{array}{c}\text { Colchicine } \\
\mathbf{h}_{\text {GR }}\end{array}$ & $\begin{array}{c}\text { Colchicine } \\
\text { GR }_{\text {AOC }}\end{array}$ \\
\hline Tyr- $\boldsymbol{\alpha}$ & -0.161 & -0.510 & 0.266 & -0.228 & -0.161 & -0.340 & 0.245 & 0.193 \\
\hline Detyr- $\boldsymbol{\alpha}$ & -0.007 & 0.350 & -0.280 & 0.039 & -0.091 & -0.112 & -0.196 & 0.168 \\
\hline $\boldsymbol{\Delta 2 - \boldsymbol { \alpha }}$ & 0.154 & 0.217 & -0.182 & 0.161 & 0.049 & -0.200 & -0.273 & 0.025 \\
\hline AcK40- $\boldsymbol{\alpha}$ & -0.238 & -0.070 & -0.014 & -0.154 & -0.259 & -0.133 & -0.280 & 0.175 \\
\hline PolyE- $\boldsymbol{\alpha}$ & -0.287 & 0.517 & 0.084 & -0.210 & -0.357 & 0.140 & 0.112 & 0.014 \\
\hline Total $\boldsymbol{\alpha}$ & -0.168 & -0.545 & -0.168 & -0.368 & -0.245 & $-0.897 * * * *$ & -0.245 & $0.701^{*}$ \\
\hline $\boldsymbol{\beta I}$ & 0.042 & -0.615 & -0.196 & -0.133 & 0.070 & -0.487 & -0.294 & 0.326 \\
\hline $\boldsymbol{\beta I I}$ & -0.147 & -0.014 & 0.028 & -0.221 & -0.259 & -0.382 & -0.077 & 0.263 \\
\hline $\boldsymbol{\beta I I I}$ & -0.343 & 0.294 & -0.217 & -0.298 & -0.427 & -0.368 & -0.287 & 0.284 \\
\hline $\boldsymbol{\beta I V}$ & $-0.720^{*}$ & -0.350 & 0.126 & $-0.823 * *$ & $-0.699 *$ & $-0.620^{*}$ & 0.154 & $0.641^{*}$ \\
\hline pS172 $\boldsymbol{\beta I I I}$ & -0.231 & 0.245 & -0.497 & -0.207 & -0.259 & -0.319 & -0.392 & 0.333 \\
\hline PolyE $\boldsymbol{\beta}$ & 0.168 & 0.189 & 0.147 & 0.308 & 0.112 & 0.151 & 0.161 & -0.207 \\
\hline Total $\boldsymbol{\beta}$ & -0.322 & -0.476 & -0.217 & -0.525 & -0.329 & $-0.616^{*}$ & -0.259 & $0.581^{*}$ \\
\hline Total $\boldsymbol{\gamma}$ & -0.224 & -0.224 & -0.126 & -0.221 & -0.252 & -0.469 & -0.133 & 0.392 \\
\hline
\end{tabular}


Table S8. Spearman's correlation coefficients between nocodazole sensitivity metrics (Table S4) with tubulin code (Figure S2). $(* \mathbf{P}<\mathbf{0 . 0 5} ; * * \mathbf{P}<\mathbf{0 . 0 1} ; * * * \mathbf{P}<\mathbf{0 . 0 0 5} ; * * * * \mathbf{P}<\mathbf{0 . 0 0 1})$

\begin{tabular}{|l|c|c|c|c|c|c|c|c|}
\hline & $\begin{array}{c}\text { Nocodazol } \\
\mathbf{e ~ I C}_{\mathbf{5 0}}\end{array}$ & $\begin{array}{c}\text { Nocodazole } \\
\mathbf{E}_{\mathbf{m a x}}\end{array}$ & $\begin{array}{c}\text { Nocodazole } \\
\mathbf{h}\end{array}$ & $\begin{array}{c}\text { Nocodazole } \\
\text { AUC }\end{array}$ & $\begin{array}{c}\text { Nocodazole } \\
\mathbf{G R}_{\mathbf{5 0}}\end{array}$ & $\begin{array}{c}\text { Nocodazole } \\
\text { GR }_{\mathbf{m a x}}\end{array}$ & $\begin{array}{c}\text { Nocodazole } \\
\mathbf{h}_{\text {GR }}\end{array}$ & $\begin{array}{c}\text { Nocodazole } \\
\text { GR }\end{array}$ \\
\hline Tyr- $\boldsymbol{\alpha}$ & -0.042 & $-0.599^{*}$ & -0.259 & -0.434 & -0.196 & -0.329 & -0.322 & 0.455 \\
\hline Detyr- $\boldsymbol{\alpha}$ & 0.406 & 0.375 & -0.357 & 0.217 & 0.098 & -0.084 & -0.385 & -0.007 \\
\hline $\boldsymbol{\Delta 2 - \boldsymbol { \alpha }}$ & 0.378 & 0.172 & -0.238 & -0.042 & 0.091 & -0.224 & -0.182 & 0.133 \\
\hline AcK40- $\boldsymbol{\alpha}$ & -0.063 & -0.053 & -0.161 & -0.021 & -0.126 & -0.077 & 0.021 & -0.063 \\
\hline PolyE- $\boldsymbol{\alpha}$ & -0.196 & $0.585^{*}$ & -0.063 & 0.000 & -0.154 & 0.175 & 0.056 & -0.182 \\
\hline Total $\boldsymbol{\alpha}$ & -0.315 & -0.501 & 0.133 & -0.503 & $-0.615^{*}$ & $-0.902^{* * *}$ & 0.098 & $0.853^{* * *}$ \\
\hline $\boldsymbol{\beta I}$ & -0.287 & $-0.588^{*}$ & 0.168 & -0.427 & -0.301 & -0.476 & 0.035 & 0.517 \\
\hline $\boldsymbol{\beta I I}$ & 0.049 & -0.032 & -0.301 & -0.350 & -0.175 & -0.357 & -0.224 & 0.350 \\
\hline $\boldsymbol{\beta I I I}$ & -0.063 & 0.273 & -0.392 & -0.385 & -0.322 & -0.315 & -0.294 & 0.294 \\
\hline $\boldsymbol{\beta I V}$ & $-0.839 * * *$ & -0.280 & 0.294 & $-0.804 * *$ & $-0.762 * *$ & -0.580 & 0.357 & $0.713^{*}$ \\
\hline pS172 $\boldsymbol{\beta I I I}$ & -0.042 & 0.301 & -0.266 & -0.259 & -0.259 & -0.252 & -0.406 & 0.287 \\
\hline PolyE $\boldsymbol{\beta}$ & $0.720^{*}$ & 0.067 & -0.406 & 0.378 & 0.392 & 0.105 & -0.329 & -0.203 \\
\hline Total $\boldsymbol{\beta}$ & $-0.692^{*}$ & -0.357 & 0.203 & $-0.706 *$ & $-0.671 *$ & -0.559 & 0.105 & $0.650^{*}$ \\
\hline Total $\boldsymbol{\gamma}$ & -0.119 & -0.161 & 0.007 & -0.448 & -0.287 & -0.441 & -0.182 & 0.531 \\
\hline
\end{tabular}


Table S9. Spearman's correlation coefficients between tivantinib sensitivity metrics (Table S5) with tubulin code (Figure S2). $(* \mathbf{P}<\mathbf{0 . 0 5} ; * * \mathbf{P}<\mathbf{0 . 0 1} ; * * * \mathbf{P}<\mathbf{0 . 0 0 5} ; * * * * \mathbf{P}<\mathbf{0 . 0 0 1})$

\begin{tabular}{|c|c|c|c|c|c|c|c|c|}
\hline & $\begin{array}{c}\text { Tivantinib } \\
\text { IC }_{50}\end{array}$ & $\begin{array}{c}\text { Tivantinib } \\
\text { Emax }_{\max }\end{array}$ & $\begin{array}{c}\text { Tivantinib } \\
\mathbf{h}\end{array}$ & $\begin{array}{c}\text { Tivantinib } \\
\text { AUC }\end{array}$ & $\begin{array}{c}\text { Tivantinib } \\
\text { GR50 }^{2}\end{array}$ & $\begin{array}{c}\text { Tivantinib } \\
\text { GR }_{\max }\end{array}$ & $\begin{array}{c}\text { Tivantinib } \\
\text { h }_{\text {GR }}\end{array}$ & $\begin{array}{c}\text { Tivantinib } \\
\text { GR }_{\text {AOC }}\end{array}$ \\
\hline Tyr- $\alpha$ & -0.287 & -0.126 & 0.224 & -0.126 & -0.378 & -0.007 & 0.224 & 0.063 \\
\hline Detyr- $\alpha$ & 0.406 & 0.217 & -0.329 & 0.441 & 0.119 & -0.196 & -0.329 & -0.154 \\
\hline$\Delta 2-\alpha$ & 0.203 & 0.483 & -0.154 & 0.294 & 0.126 & -0.168 & -0.154 & -0.098 \\
\hline AcK40- $\alpha$ & 0.105 & -0.378 & -0.217 & -0.203 & 0.154 & -0.308 & -0.217 & 0.273 \\
\hline PolyE- $\alpha$ & 0.294 & 0.350 & -0.238 & 0.126 & 0.224 & -0.077 & -0.238 & -0.063 \\
\hline Total $\alpha$ & -0.490 & 0.028 & $0.566 *$ & -0.427 & $-0.776 * *$ & $-0.615^{*}$ & 0.566 & 0.580 \\
\hline$\beta I$ & $-0.685^{*}$ & -0.287 & 0.476 & -0.483 & $-0.622 *$ & -0.154 & 0.476 & 0.378 \\
\hline$\beta I I$ & 0.000 & 0.245 & -0.042 & -0.007 & -0.126 & -0.259 & -0.042 & 0.140 \\
\hline$\beta I I I$ & -0.021 & 0.343 & -0.077 & 0.070 & -0.147 & -0.294 & -0.077 & 0.056 \\
\hline$\beta I V$ & $-0.720^{*}$ & -0.098 & 0.643 & $-0.748 * *$ & $-0.769 * *$ & -0.420 & 0.643 & 0.664* \\
\hline pS172 $\beta$ III & -0.203 & 0.231 & 0.014 & 0.140 & -0.357 & -0.161 & 0.014 & -0.042 \\
\hline PolyE $\beta$ & $0.685^{*}$ & 0.245 & -0.434 & $0.629 *$ & 0.497 & 0.035 & -0.434 & -0.392 \\
\hline Total $\beta$ & $-0.783 * *$ & -0.133 & 0.503 & $-0.622^{*}$ & $-0.797 * *$ & -0.280 & 0.503 & 0.524 \\
\hline Total $\gamma$ & -0.462 & 0.189 & 0.322 & -0.126 & $-0.510 *$ & -0.231 & 0.322 & 0.154 \\
\hline
\end{tabular}


Table S10. Spearman's correlation coefficients between CMPD1 sensitivity metrics (Table S6) with tubulin code (Figure S2). $(* \mathbf{P}<0.05 ; * * \mathbf{P}<\mathbf{0 . 0 1} ; * * * \mathbf{P}<\mathbf{0 . 0 0 5} ; * * * * \mathbf{P}<\mathbf{0 . 0 0 1})$

\begin{tabular}{|l|c|c|c|c|c|c|c|c|}
\hline & $\begin{array}{c}\text { CMPD1 } \\
\text { IC50 }\end{array}$ & $\begin{array}{c}\text { CMPD1 } \\
\mathbf{E m a x}_{\mathbf{m a x}}\end{array}$ & $\begin{array}{c}\text { CMPD1 } \\
\mathbf{h}\end{array}$ & $\begin{array}{c}\text { CMPD1 } \\
\text { AUC }\end{array}$ & $\begin{array}{c}\text { CMPD1 } \\
\text { GR50 }\end{array}$ & $\begin{array}{c}\text { CMPD1 } \\
\text { GRmax }\end{array}$ & $\begin{array}{c}\text { CMPD1 } \\
\text { hGR }\end{array}$ & $\begin{array}{c}\text { CMPD1 } \\
\text { GRAOC }\end{array}$ \\
\hline Tyr- $\boldsymbol{\alpha}$ & $-0.601^{*}$ & -0.336 & 0.252 & $-0.755^{* *}$ & $-0.636^{*}$ & -0.154 & 0.238 & 0.420 \\
\hline Detyr- $\boldsymbol{\alpha}$ & 0.406 & 0.503 & -0.490 & 0.434 & 0.021 & -0.077 & -0.517 & 0.098 \\
\hline $\boldsymbol{\Delta 2 - \boldsymbol { \alpha }}$ & 0.245 & 0.280 & -0.238 & 0.315 & -0.161 & -0.133 & -0.322 & 0.119 \\
\hline AcK40- $\boldsymbol{\alpha}$ & 0.028 & -0.413 & 0.035 & 0.182 & -0.035 & -0.245 & -0.056 & -0.063 \\
\hline PolyE- $\boldsymbol{\alpha}$ & 0.287 & 0.336 & 0.000 & 0.503 & 0.168 & 0.126 & -0.035 & -0.231 \\
\hline Total $\boldsymbol{\alpha}$ & -0.510 & -0.280 & 0.140 & -0.392 & $-0.818^{* *}$ & $-0.846^{* * *}$ & 0.084 & $0.874^{* * *}$ \\
\hline $\boldsymbol{\beta I}$ & -0.497 & -0.510 & 0.063 & $-0.608^{*}$ & -0.490 & -0.476 & 0.070 & 0.538 \\
\hline $\boldsymbol{\beta I I}$ & -0.098 & -0.098 & 0.000 & -0.028 & -0.448 & -0.294 & -0.091 & 0.308 \\
\hline $\boldsymbol{\beta I I I}$ & 0.126 & 0.252 & -0.238 & 0.175 & -0.322 & -0.252 & -0.294 & 0.252 \\
\hline $\boldsymbol{\beta I V}$ & $-0.622^{*}$ & -0.406 & 0.490 & -0.566 & $-0.615^{*}$ & $-0.559^{*}$ & 0.476 & $0.657^{*}$ \\
\hline pS172 $\boldsymbol{\beta I I I I}$ & 0.168 & 0.483 & -0.538 & 0.063 & -0.210 & -0.203 & $-0.517^{*}$ & 0.371 \\
\hline PolyE $\boldsymbol{\beta}$ & 0.252 & 0.371 & -0.119 & 0.273 & 0.056 & 0.238 & -0.189 & -0.182 \\
\hline Total $\boldsymbol{\beta}$ & -0.552 & -0.448 & 0.133 & -0.531 & $-0.608^{*}$ & $-0.601 *$ & 0.098 & $0.643^{*}$ \\
\hline Total $\boldsymbol{\gamma}$ & -0.308 & 0.098 & -0.077 & -0.371 & -0.559 & -0.315 & -0.091 & $0.608^{*}$ \\
\hline
\end{tabular}


Figure S1.

Standard Classical Mesenchymal Proneural

㐫

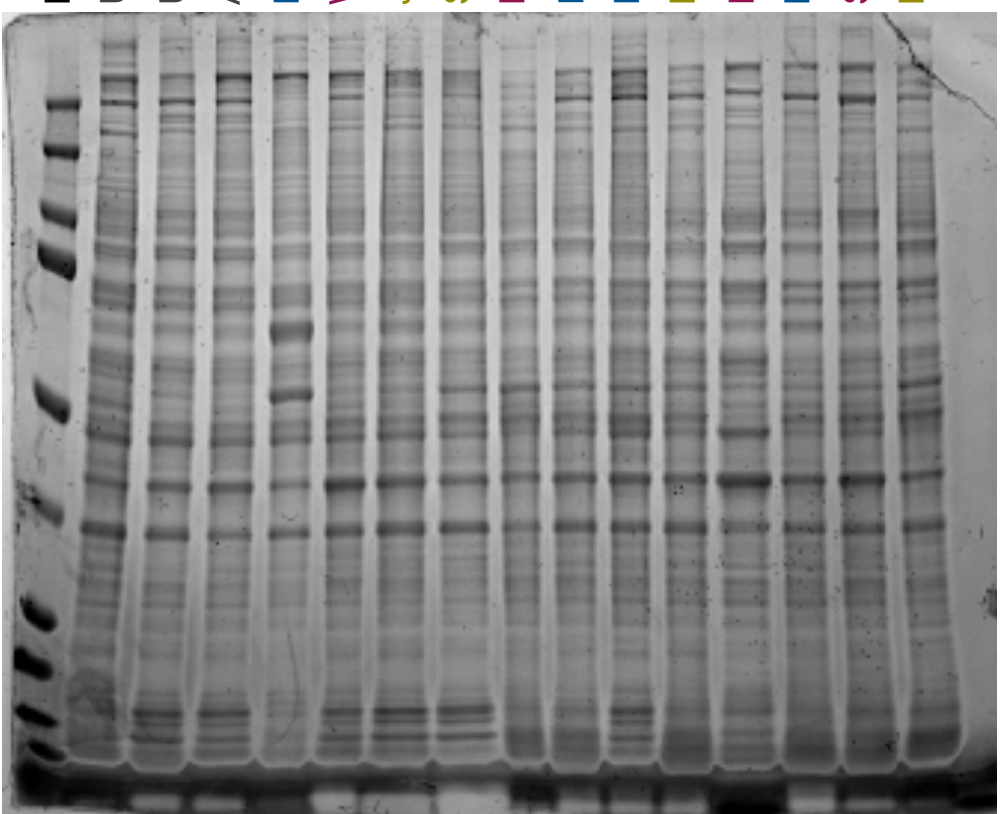

Figure S1. Representative image of Coomassie stained gel to demonstrate equal protein load across 15 cell lines. 
a

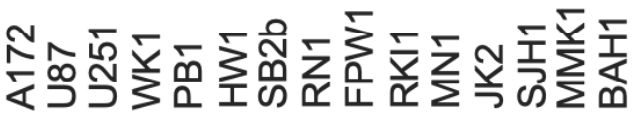

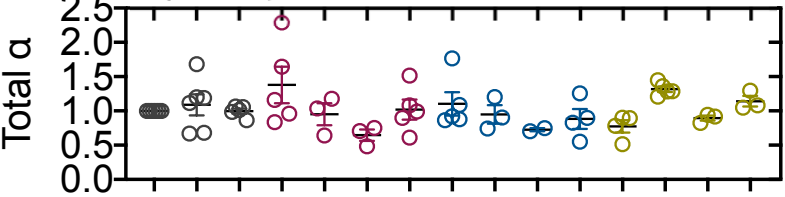

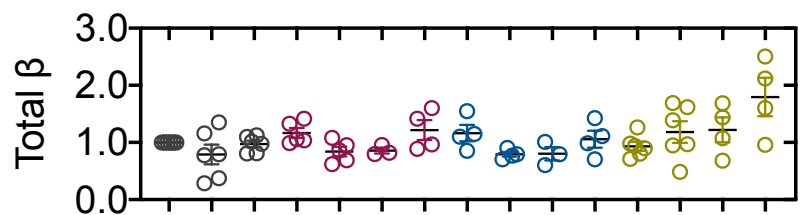

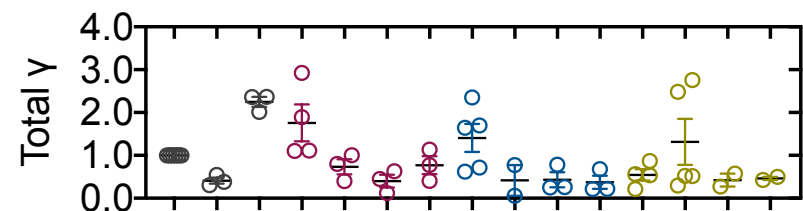
2.5
2.0
1.5
1.0
0.5
0.0 $\left.\overline{\overline{0}} \begin{array}{l}8.0 \\ 6.0 \\ 4.0 \\ 2.0 \\ 0.0\end{array}\right]_{1}^{1}$

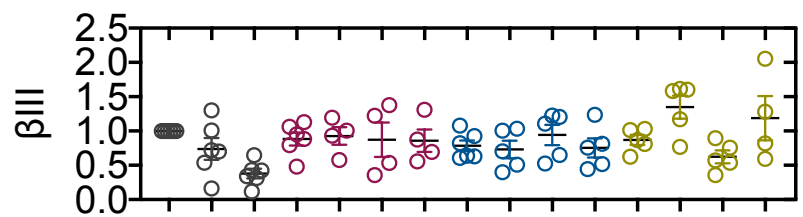

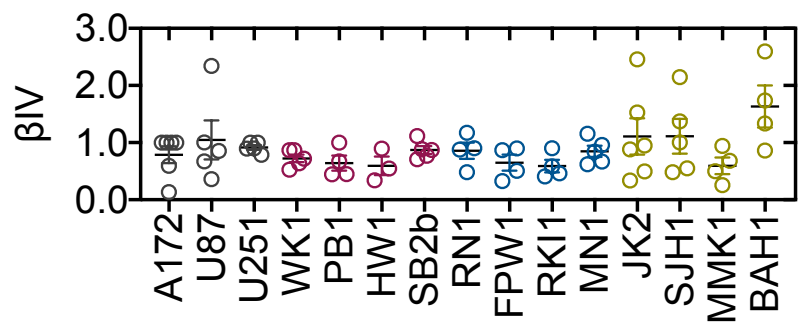

b

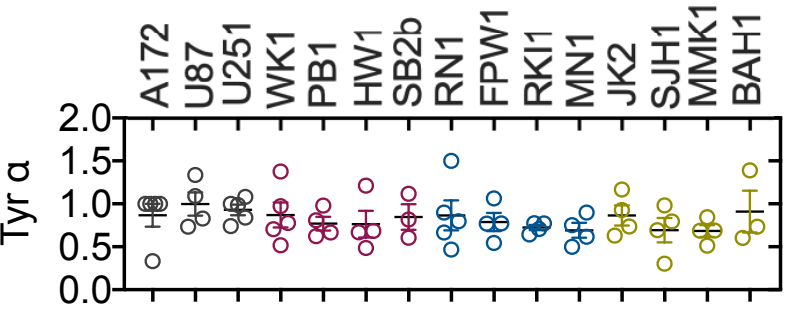

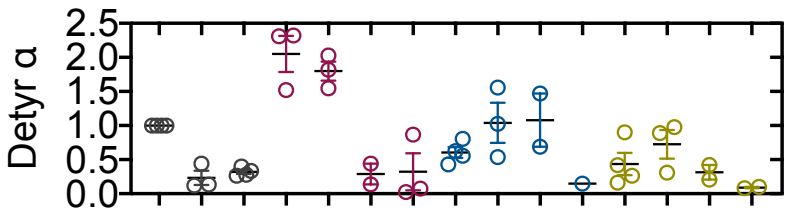
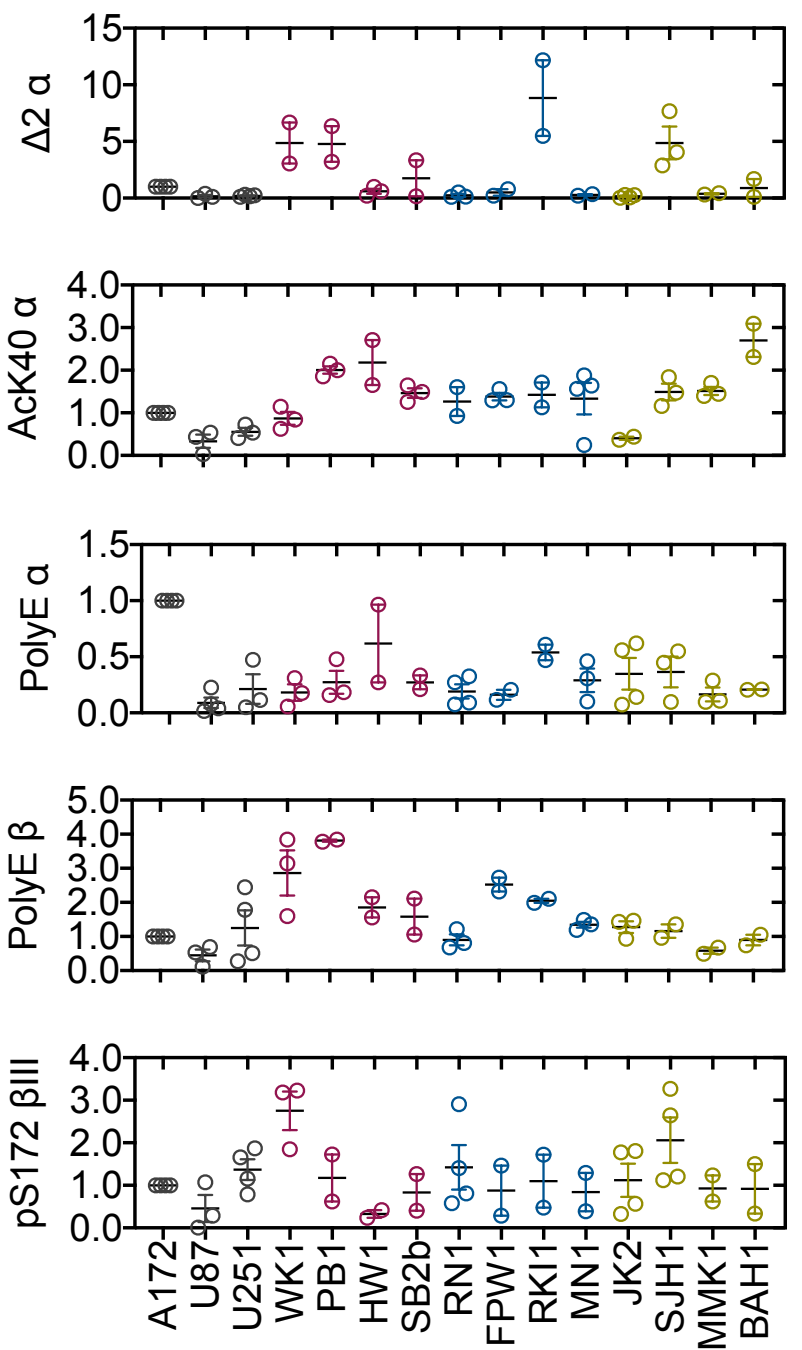

Figure S2. Expression of tubulin isotypes and post-translational modifications normalised to A172

signals. Cell lysates ( $5 \mu \mathrm{g}$ total protein) were analysed by Western blotting using specific antibodies. Representative immunoblots are shown in Figure 1. Quantifications of tubulin isotypes (a) and posttranslational modifications (b) are presented as fold change relative to $A 172$ (set as 1). Data are mean \pm SEM $(n=4-6)$. 


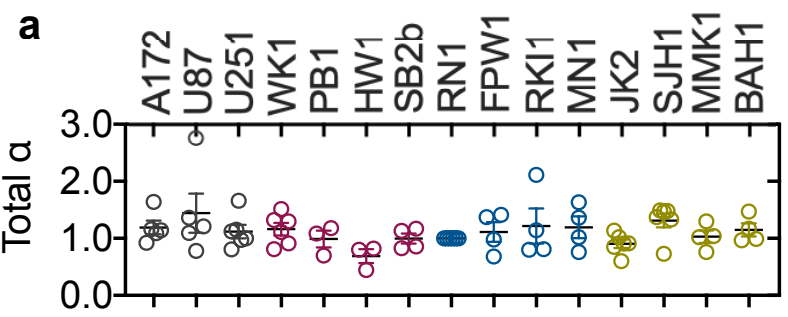

b

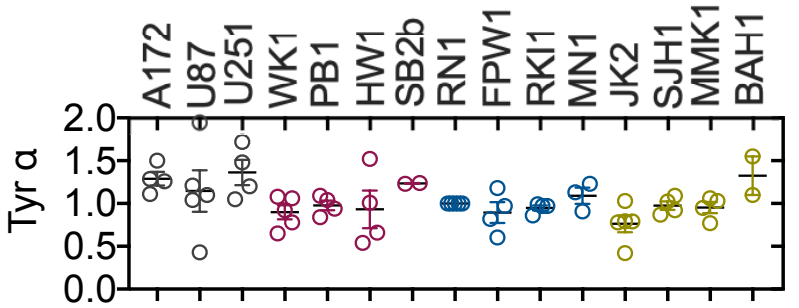

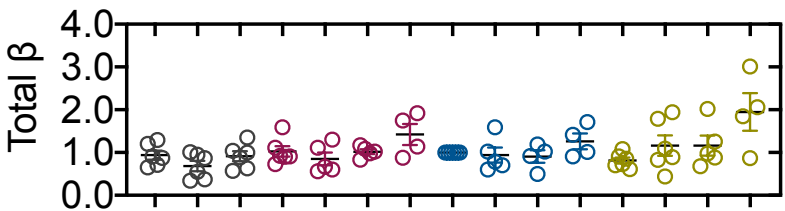
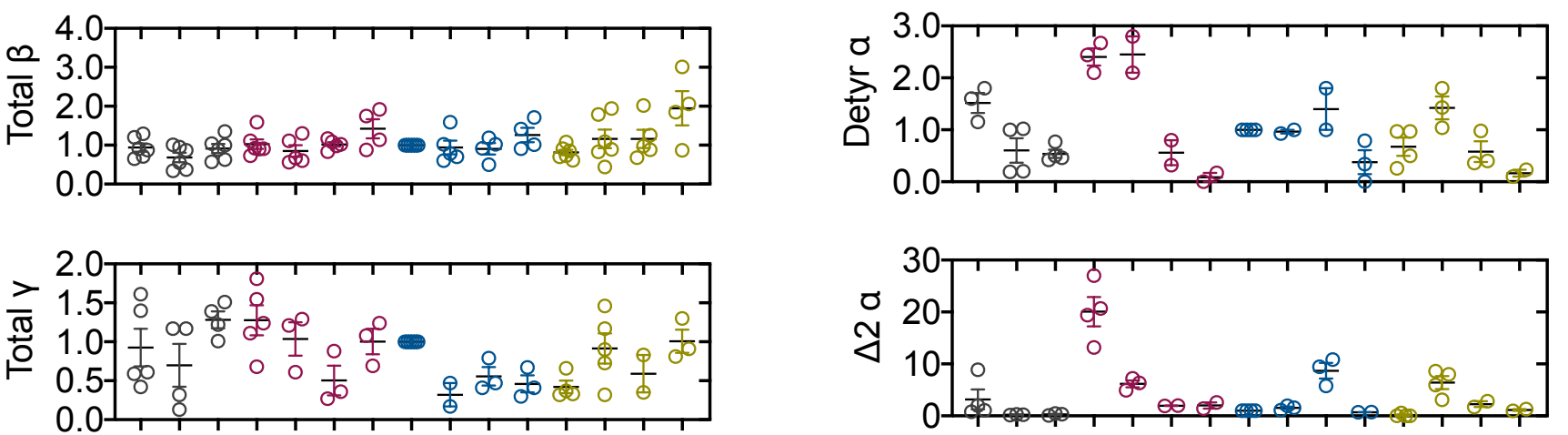

$\left.\begin{array}{lllllllll}2.0 \\ 1.5 \\ 1.0 \\ 0 \\ 0.5 \\ 0.0\end{array}\right]$
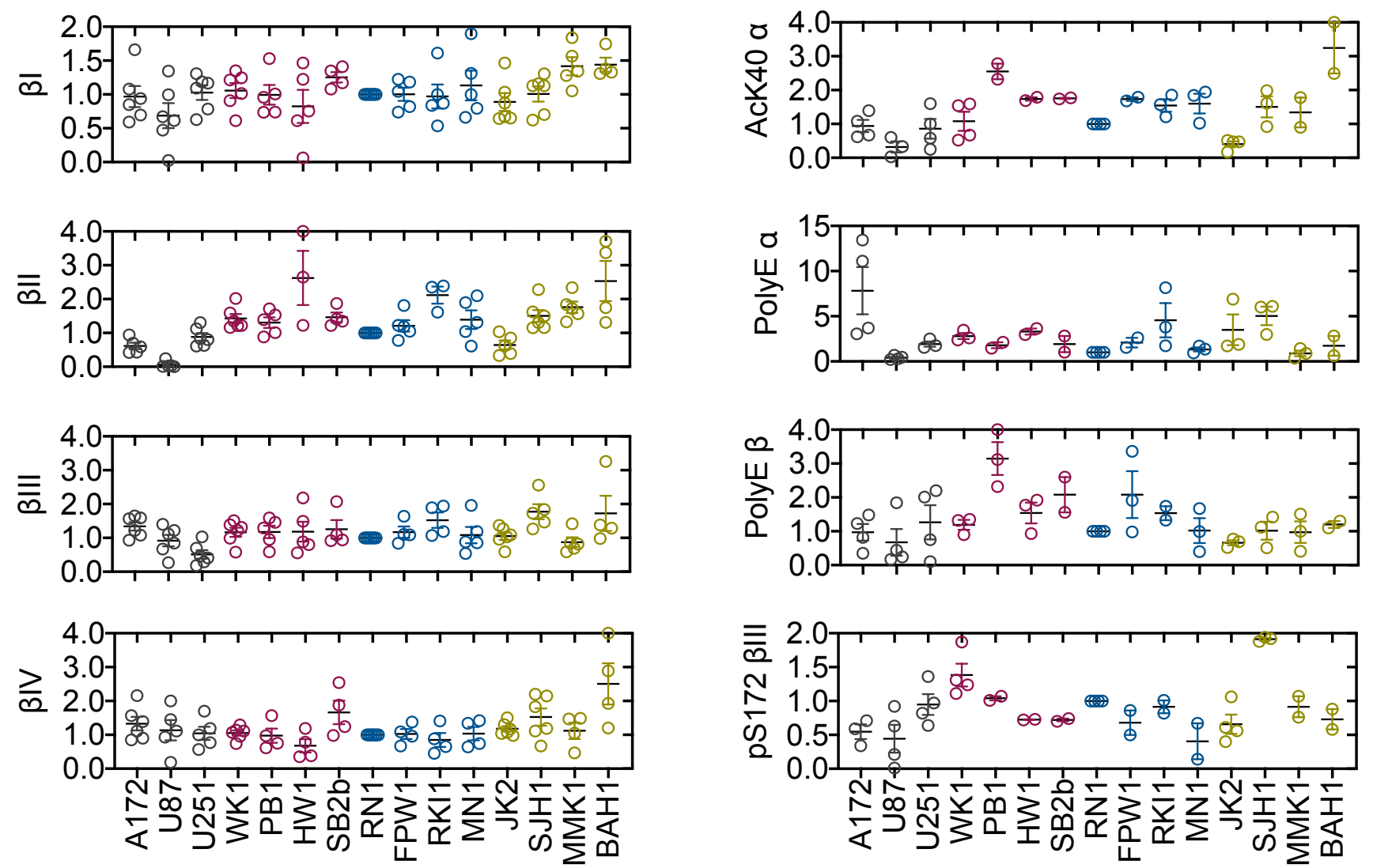

Figure S3. Expression of tubulin isotypes and post-translational modifications normalised to RN1

signals. Cell lysates ( $5 \mu \mathrm{g}$ total protein) were analysed by Western blotting using specific antibodies.

Representative immunoblots are shown in Figure 1. Quantifications of tubulin isotypes (a) and posttranslational modifications (b) are presented as fold change relative to RN1 (set as 1). Data are mean \pm SEM $(n=4-6)$. 

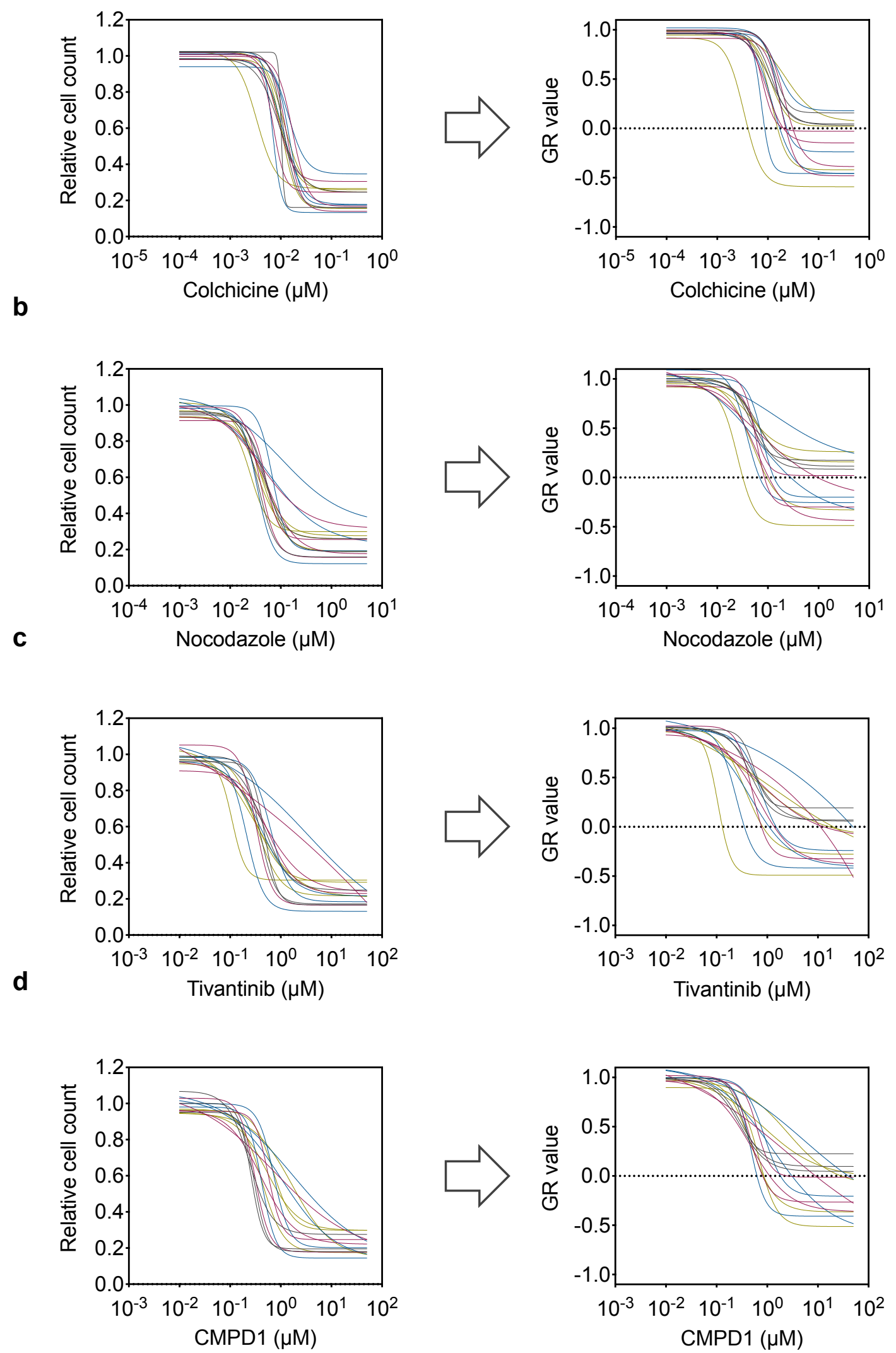

Figure S4. Dose-response curves for MTAs in glioblastoma cell lines. Relative and GR doseresponse curves for (a) colchicine, (b) nocodazole, (c) tivantinib and (d) CMPD1 were generated from dose responses determined with CellTiter-Blue viability assay after 5 days of drug treatment and doubling time using the GRcalculator tool. Each curve represents the mean of three independent cell viability assays, where each data point was done in triplicate. 


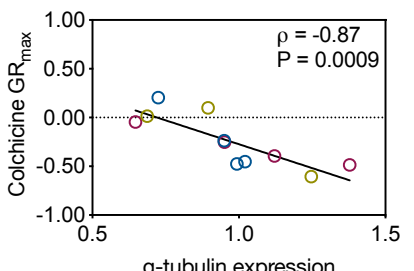

b
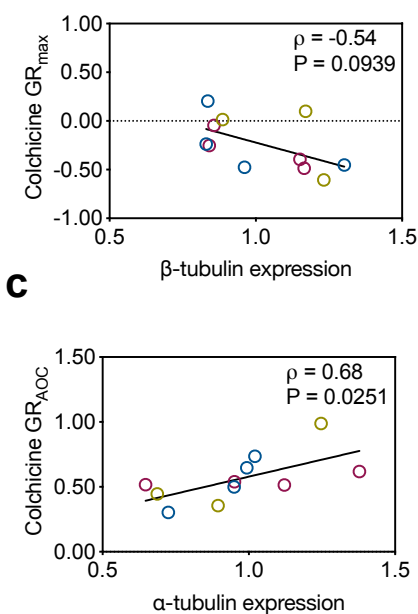

d

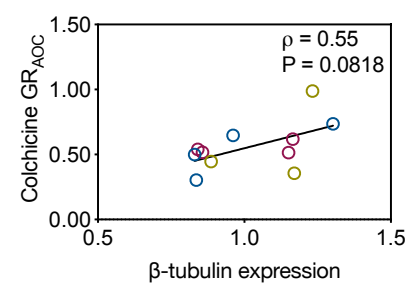

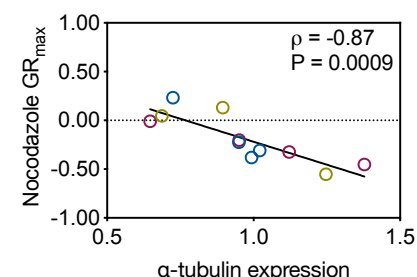

a-tubulin expression
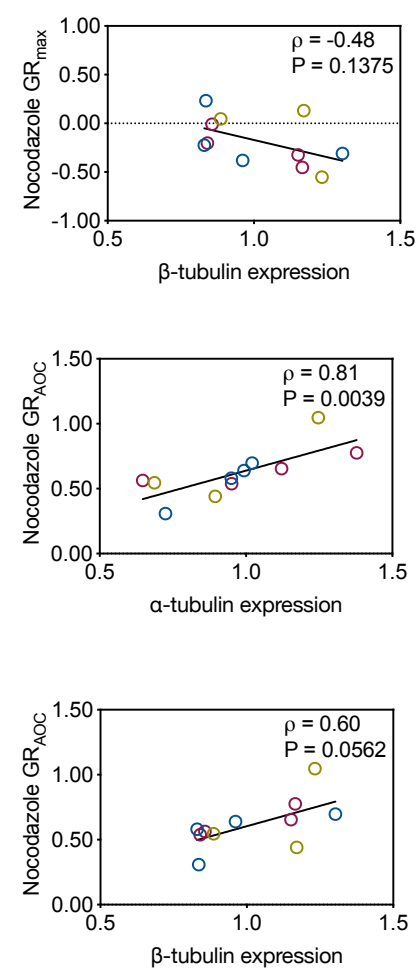
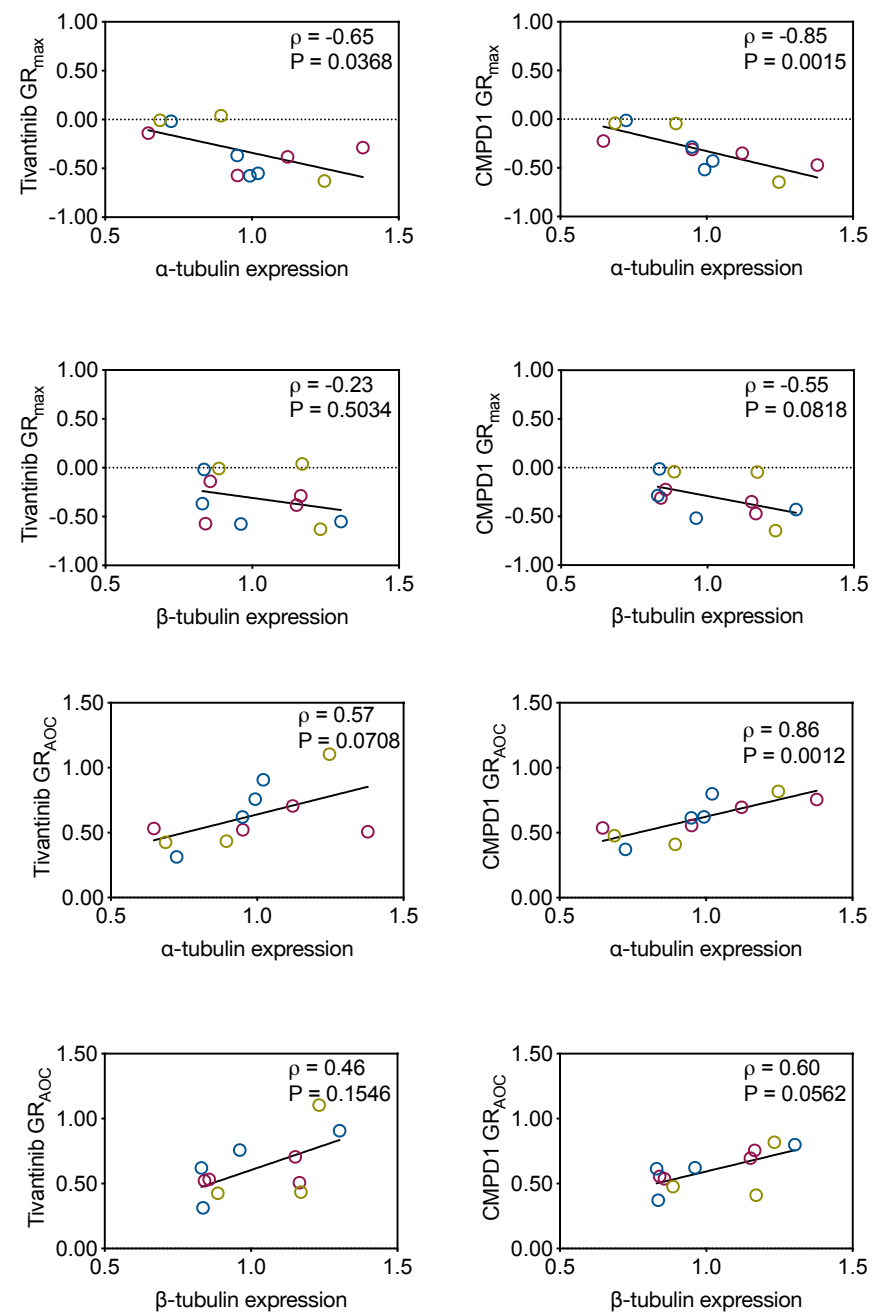

Figure S5. Spearman's correlations between tubulin expression and MTAs efficacy excluding

BAH1 data. Pairwise distribution and correlation of $\mathrm{GR}_{\max }$ and the expression of (a) $\alpha$-tubulin and (b) $\beta$ tubulin in glioblastoma stem cell lines. Pairwise distribution and correlation of $\mathrm{GR}_{\mathrm{AOC}}$ and the expression of (c) $\alpha$-tubulin and (d) $\beta$-tubulin in glioblastoma stem cell lines. 
a

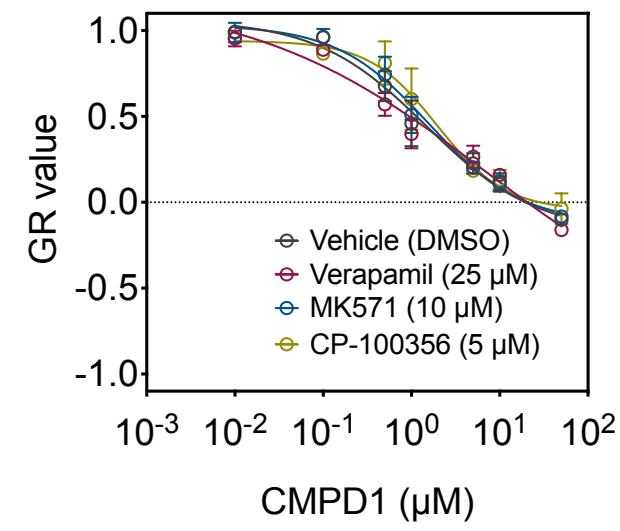

b

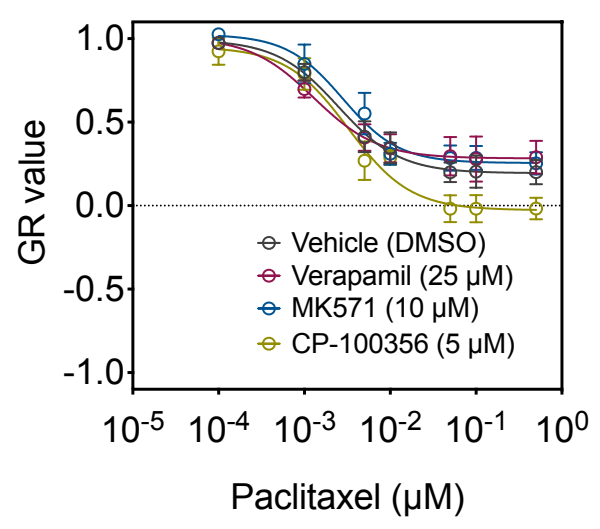

C

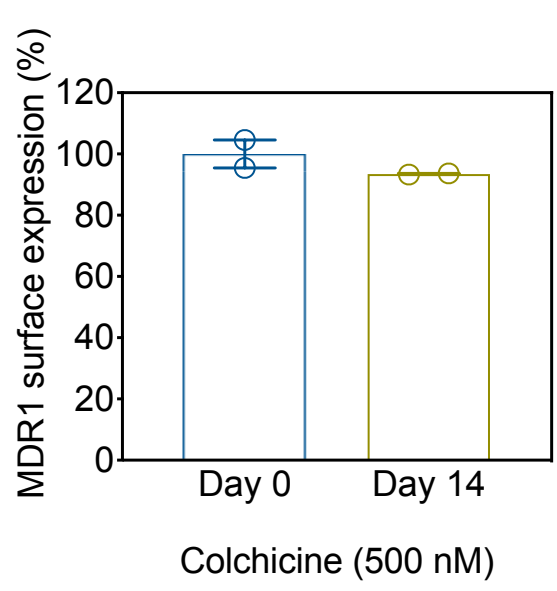

d
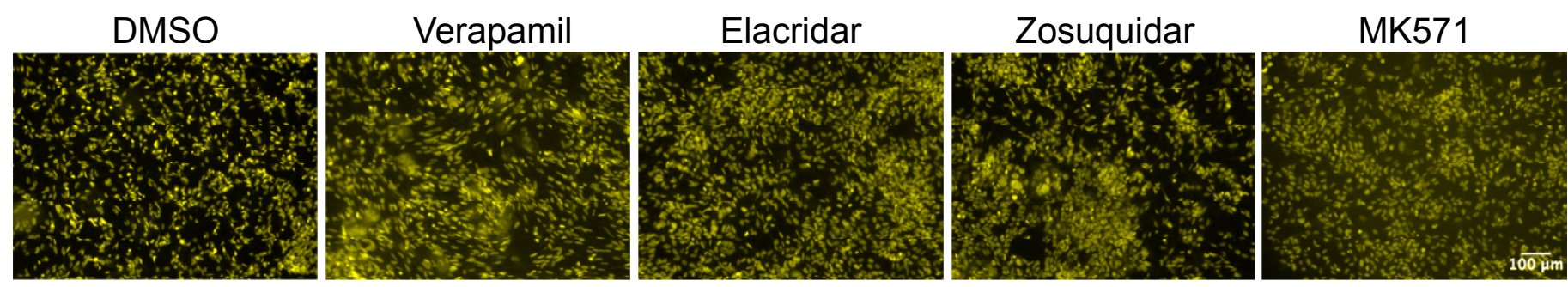

Figure S6. Inhibitors of efflux pumps do not alter the efficacy of MTAs in RKI1 cells.

GR dose-response curves for (a) CMPD1 or (b) paclitaxel in the presence or absence of efflux pump inhibitor verapamil, MK571 or CP-100356 were generated from dose-response curves of RKI1 cells obtained in a 5 day CellTiter-Blue viability assay and RKI1 doubling time. Each curve is a mean of three independent cell viability assays, where each data point was performed in triplicate. (c) RKI1 cells were treated with colchicine (500 nM, 14 days) then stained with FITC-conjugated CD243 (MDR-1) antibody and analysed by flow cytometry. Geometric mean of CD243 surface expression was graphed using Prism v7.0 (GraphPad). Data are mean \pm SEM from 3 independent experiments. 